\title{
Target-cell-specific short-term plasticity in local circuits
}

\section{Arne V. Blackman ${ }^{1}$, Therese Abrahamsson ${ }^{2}$, Rui Ponte Costa ${ }^{3}$, Txomin Lalanne $^{2,4}$ and P. Jesper Sjöström ${ }^{1,2 *}$}

\author{
1 Department of Neuroscience, Physiology and Pharmacology, University College London, London, UK \\ 2 Department of Neurology and Neurosurgery, Centre for Research in Neuroscience, The Research Institute of the McGill University Health Centre, Montreal \\ General Hospital, Montreal, QC, Canada \\ ${ }^{3}$ Neuroinformatics Doctoral Training Centre, School of Informatics, Institute for Adaptive and Neural Computation, University of Edinburgh, Edinburgh, UK \\ ${ }^{4}$ Integrated Program in Neuroscience, McGill University, Montreal, QC, Canada
}

\author{
Edited by: \\ Christian Tetzlaff, Georg-August \\ University, Germany \\ Reviewed by: \\ Gilad Silberberg, Karolinska \\ Institute, Sweden \\ Ileana Hanganu-Opatz, University of \\ Hamburg, Germany \\ Jean-Pascal Pfister, University of \\ Cambridge, UK (in collaboration with \\ Simone Surace) \\ ${ }^{*}$ Correspondence: \\ P. Jesper Sjöström, Department of \\ Neurology and Neurosurgery, \\ Centre for Research in \\ Neuroscience, The Research \\ Institute of the McGill University \\ Health Centre, Montreal General \\ Hospital, 1650 Cedar Ave., Room \\ L7-225, Montreal, QC H3G 1A4, \\ Canada \\ e-mail: jesper.sjostrom@mcgill.ca
}

Short-term plasticity (STP) denotes changes in synaptic strength that last up to tens of seconds. It is generally thought that STP impacts information transfer across synaptic connections and may thereby provide neurons with, for example, the ability to detect input coherence, to maintain stability and to promote synchronization. STP is due to a combination of mechanisms, including vesicle depletion and calcium accumulation in synaptic terminals. Different forms of STP exist, depending on many factors, including synapse type. Recent evidence shows that synapse dependence holds true even for connections that originate from a single presynaptic cell, which implies that postsynaptic target cell type can determine synaptic short-term dynamics. This arrangement is surprising, since STP itself is chiefly due to presynaptic mechanisms. Target-specific synaptic dynamics in addition imply that STP is not a bug resulting from synapses fatiguing when driven too hard, but rather a feature that is selectively implemented in the brain for specific functional purposes. As an example, target-specific STP results in sequential somatic and dendritic inhibition in neocortical and hippocampal excitatory cells during high-frequency firing. Recent studies also show that the Elfn1 gene specifically controls STP at some synapse types. In addition, presynaptic NMDA receptors have been implicated in synapse-specific control of synaptic dynamics during high-frequency activity. We argue that synapse-specific STP deserves considerable further study, both experimentally and theoretically, since its function is not well known. We propose that synapse-specific STP has to be understood in the context of the local circuit, which requires combining different scientific disciplines ranging from molecular biology through electrophysiology to computer modeling.

Keywords: short-term plasticity, synapse specificity, synaptic disease, network models, synapse formation, development

\section{INTRODUCTION}

The functioning of the brain is governed by its neuronal connectivity and by the synaptic dynamics of these connections. Learning and information storage in the brain, for example, are widely thought to be due to long-term changes in connective strength, as postulated by Donald Hebb (1949) and others before him (Markram et al., 2011). Such changes last for hours, days, and weeks. But there are also other forms of synaptic plasticity that are active on considerably faster time scales, such as short-term depression and facilitation, and these last from a few milliseconds to tens of seconds (Zucker and Regehr, 2002; Abbott and Regehr, 2004).

Synaptic short-term plasticity (STP) is thought to result from a combination of mechanisms, chiefly presynaptic ones, including vesicle depletion and accumulation of calcium in the presynaptic terminal during prolonged high-frequency activity, but desensitization of postsynaptic neurotransmitter receptors also matter (Zucker and Regehr, 2002; Thomson, 2003; Abbott and Regehr, 2004; Fioravante and Regehr, 2011). STP is not an epiphenomenal synaptic defect due to fatigue during high-frequency activity, but rather a feature that the brain relies on to process information and to maintain the balance of excitation and inhibition. Indeed, STP depends specifically on factors such as developmental age (Pouzat and Hestrin, 1997; Reyes and Sakmann, 1999; Cheetham and Fox, 2010), neocortical layer (Reyes and Sakmann, 1999), brain area (Wang et al., 2006; Cheetham and Fox, 2010), postsynaptic cell-type (Markram et al., 1998; Beierlein et al., 2003; Buchanan et al., 2012), and sensory experience (Finnerty et al., 1999; Cheetham and Fox, 2011; Liu et al., 2012). Differences in STP have been identified at connections between two neocortical pyramidal cells (PCs) and those from PCs to various interneurons (INs) (Thomson et al., 1996). For example, connections from PCs to basket cells (BCs) typically exhibit short-term depression, whereas those from PCs to Martinotti cells (MCs) show striking facilitation (Figure 1A) (Markram et al., 1998; Reyes et al., 1998; Buchanan et al., 2012). Because the type of STP that is active at a given synapse type critically determines the type of information it transfers, the same presynaptic cell may thus transmit quite different information to different classes of postsynaptic cells (Markram et al., 1998). As an illustration, short-term depressing and facilitating synapses optimally transfer information at low and high frequencies, respectively (Fuhrmann et al., 


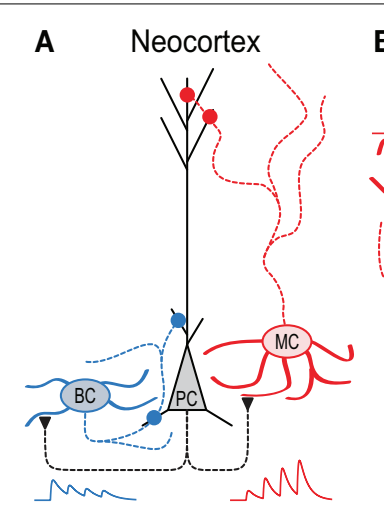

FIGURE 1 | In local circuits, target-cell specific STP remaps spiking across the somato-dendritic axis. (A) Pyramidal cell (PC) inputs to basket cells $(\mathrm{BC})$ are short-term depressing, whereas those to Martinotti cells (MC) are facilitating (Markram et al., 1998). As a result, high-frequency PC firing (Larkum et al., 1999; Murayama et al., 2009) activates MCs later than BCs, an effect that is amplified by presynaptic NMDA receptors (Figure $\mathbf{3}$ and Buchanan et al., 2012). BCs in turn innervate PCs perisomatically (Buchanan et al., 2012), whereas MCs contact the apical dendrite (Silberberg and Markram, 2007). (B) In cerebellum, synapses between parallel fibers (PF) and Purkinje cells (PuC) facilitate, as do connections to stellate cells (SC). In contrast, PF synapses onto BCs depress, so high-frequency PF activity

\section{B Cerebellum $\quad$ C Hippocampus CA1}

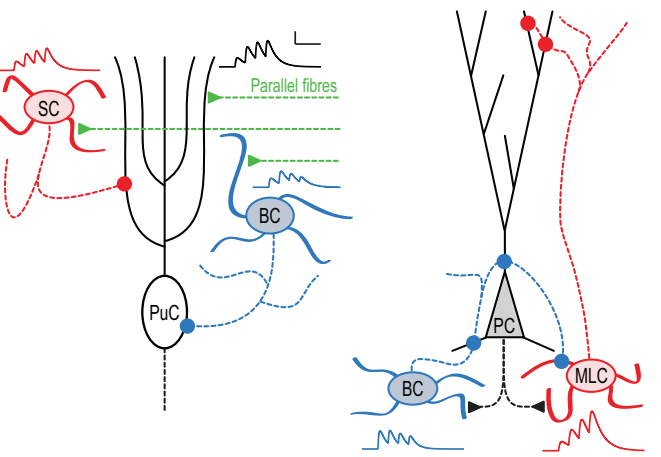

triggers SCs later than BCs, leading to early onset somatic and late-onset dendritic PuC inhibition (Bao et al., 2010). (C) In hippocampus CA1, PCs connect to two distinct stratum oriens IN types with contrasting STP. Onset-transient BCs receive depressing input and target PCs and other INs perisomatically, whilst late-transient Martinotti-like cells (MLC) receive facilitating input and target dendrites (although see Hefft and Jonas, 2005; Glickfeld and Scanziani, 2006). During $50 \mathrm{~Hz}$ firing therefore, inhibition of PCs shifts from somatic to dendritic (Pouille and Scanziani, 2004). Early-onset BC inhibition of MLCs may additionally amplify this effect (Lovett-Barron et al., 2012). All synaptic traces were simulated based on data in (Pouille and Scanziani, 2004; Bao et al., 2010; Buchanan et al., 2012).
2002). Short-term depression also emphasizes temporal coherence of inputs at the expense of rate coding, and these different synaptic dynamics may result in quite distinct regular or irregular activity regimes in recurrently connected networks (Tsodyks and Markram, 1997; Tsodyks et al., 1998).

Here, we overview target-cell-specific STP in local circuits and discuss its potential mechanisms as well as its functional implications.

\section{FUNCTIONAL IMPLICATIONS OF STP}

One of the most obvious functional implications of STP is that it filters information flow across the synapse (Dittman et al., 2000; Fortune and Rose, 2001; Fuhrmann et al., 2002). For example, a facilitating connection, e.g., from a PC to an MC (Figure 1A), requires several spikes to elicit suprathreshold responses in the MC. A PC-MC connection thus constitutes a high-pass filter, since only high-frequency trains elicit postsynaptic spikes. Conversely, a short-term depressing synapse-such as that between a PC and a BC (Figure 1A) - may trigger spikes in the recipient cell after the first few spikes, after which it needs to recover to the initial high-release state. Low frequencies are therefore more efficacious than high frequencies at bringing the postsynaptic cell to threshold, which corresponds to a lowpass filter. Intermediate forms of plasticity may elicit band-pass filtering.

Because they act as high-pass filters, facilitating synapses may function as burst detectors (Maass and Zador, 1999; Matveev and Wang, 2000). Lisman (1997) proposed that bursts are particularly important for information coding in several brain regions. Bursts are more reliable at carrying information than single spikes, which is useful as individual spikes may result from noise. Indeed, bursts are particularly reliable triggers of long-term plasticity and of information storage (e.g., Pike et al., 1999; Nevian and Sakmann, 2006). The hippocampal CA1 region in particular may have STP tuned for burst detection (Klyachko and Stevens, 2006).

However, bursting may also limit long-term plasticity. In neocortex, bursting PCs recruit MCs (Murayama et al., 2009) because of the strongly facilitating PC-MC connection (Figure 1A). MCs in turn form inhibitory synapses on the distal apical dendrite of PCs that are well suited to self-limit high-frequency excitatory firing in neocortex (Silberberg and Markram, 2007; Berger et al., 2009, 2010). Because Hebbian plasticity of excitatory inputs onto the distal apical dendrite of layer-5 PCs (Figure 1A) requires dendritic depolarization (Sjöström and Häusser, 2006), highfrequency firing may thus via MCs reduce potentiation.

Just like facilitation enables burst detection, short-term depression can help decorrelate and regularize activity (Goldman et al., 1999) (although it can also promote synchrony in some cases, see Tsodyks et al., 2000). In general, short-term depression of excitatory inputs is likely to help stabilize activity in local circuits, by rendering neurons sensitive to changes in input frequency rather than to the absolute rates (Abbott et al., 1997; Tsodyks and Markram, 1997). STP may thus provide neuronal circuits with a degree of self-stabilization, by ensuring that synaptic drive rapidly dies off during high-frequency activation. In addition, excitatory synapses may depress faster than some inhibitory connections do, thus shifting the balance of excitation and inhibition in favor of the latter during high-frequency firing (Galarreta and Hestrin, 1998; Varela et al., 1999). However, connections from neocortical PCs to BCs tend to short-term depress slightly faster than those between PCs (Costa et al., 2013). Nevertheless, STP generally helps restrict activity levels, even at relatively low rates (Sussillo et al., 2007). Differences in STP at PC-PC and PC-IN connections result in different cell types being 
maximally activated at different times, an effect that is contextdependent. Cross-correlations between PCs and facilitating INs show greater peak lag values than those between PCs, or to depressing INs; an effect that is dependent on patterned presynaptic activity (Silberberg et al., 2004). Evidence suggests that PV and SOM INs are involved with normalizing, divisive inhibition and subtractive, response selectivity sharpening inhibition, respectively (Wilson et al., 2012). As inputs to these cell types exhibit differing STP, this may control the relative timing of these functions during network activity.

Conversely, facilitation may help sustain activity, which is essential for the proper functioning of several neuronal circuit types. In working memory tasks, critical information is temporarily held in the form of persistent activity in prefrontal cortex while awaiting a relevant cue (Goldman-Rakic, 1995). Although the precise mechanisms of working memory circuits remain unclear, prefrontal cortex PCs interconnect with synapses that are more facilitating than in other cortical regions (Wang et al., 2006). Computer modeling revealed that facilitating synapses might sustain persistent activity in working memory (Mongillo et al., 2008; Hansel and Mato, 2013). Increased synaptic augmentation in prefrontal circuits has also been implicated (Varela et al., 1997; Hempel et al., 2000). In agreement, disruption of the gene Dgcr8, which affects STP in prefrontal cortex layer-5 PCs, also impacts working memory performance (Fenelon et al., 2011; Arguello and Gogos, 2012).

STP can also help explain adaptation. For example, stimulusevoked suprathreshold responses in barrel cortex quickly reduce to subthreshold levels when repeated, which has been directly linked to short-term depression of thalamocortical afferents (Chung et al., 2002). In visual cortex, short-term depression explains contrast adaptation (Chance et al., 1998), and inputspecific short-term depression explains stimulus-specific adaptation (Chance and Abbott, 2001). Differences in STP may also explain differential sensitivity of auditory pathways to timing and intensity (MacLeod, 2011). Differential target-specific changes in STP at thalamic inputs to two cortical IN types may serve to compensate for reduced sound-driven activity in animals with developmental sensorineural hearing loss (Takesian et al., 2013).

\section{STP IS TARGET CELL SPECIFIC}

Early evidence from crustacean muscle fibers suggested that terminals originating from the same motor axon might exhibit facilitation or depression depending on postsynaptic target (Atwood, 1967; Atwood and Bittner, 1971). Because target-cell-specific synaptic transmission could be essential for controlling functionally distinct components of neuronal circuits, several studies have since focused on this issue in the mammalian central nervous system (Toth and McBain, 2000; Thomson, 2003; Pelkey and McBain, 2007).

Much evidence for target-specific STP has been found in neocortex. PCs typically interconnect with depressing synapses, whilst PC connections to some IN types facilitate (Markram et al., 1998; Gupta et al., 2000). In layer 2/3, PCs form facilitating synapses with bitufted INs expressing somatostatin (SOM), but establish depressing synapses onto multipolar INs expressing parvalbumin (PV) (Reyes et al., 1998; Rozov et al., 2001). Presynaptic bouton calcium signals at these connections also depend on the target cell: connections to bitufted INs exhibit small calcium signals, whilst connections to multipolar INs show three times larger calcium signals (Koester and Johnston, 2005). Optical quantal analysis also suggests that $p_{\text {release }}$ is specific to the target cell, with different synaptic contacts of the same connection exhibiting similar release probabilities (Koester and Johnston, 2005). In layer 5, similar differences in STP are seen as in layer 2/3, with depressing PC-PC, facilitating PC-SOM IN and depressing PC-PV IN synapses (see Figure 1A, below and Buchanan et al., 2012). As SOM-positive INs typically target PC apical dendrites, whilst PVpositive INs are often perisomatic-targeting BCs (Markram et al., 2004), the differences in STP seen from PCs to these cell types can result in inhibition hyperpolarising PC somata and dendrites in sequence during high-frequency firing (Figure 1A and Buchanan et al., 2012).

In the cerebellum, target-specific STP can be seen at parallel fiber (PF) connections from granule cells to Purkinje cells and basket or stellate INs, with similar functional consequences. Whilst PF synapses onto Purkinje or stellate cells exhibit persistent facilitation, PF inputs to BCs display short-term depression following initial paired-pulse facilitation (Bao et al., 2010). As seen onto Golgi cells, deletion of the presynaptic protein Munc13 increases facilitation at PF-BC synapses (Beierlein et al., 2007; Bao et al., 2010). This target-specific STP suggests specific functionality, since BCs target Purkinje cells perisomatically, whereas stellate cells innervate their dendrites (Figure 1B). As inputs to BCs short-term depress while those to stellate cells facilitate, highfrequency granule cell firing (Chadderton et al., 2004) recruits BCs first, with stellate cells lagging. As in neocortex, PFs may thus hyperpolarize Purkinje cell soma and dendrites sequentially (Bao et al., 2010) (see below and Pouille and Scanziani, 2004).

Within hippocampal CA1, PCs contact PV-positive SO INs with depressing, high $p_{\text {release }}$ connections, and different INs with facilitating, low $p_{\text {release }}$ synapses (Thomson, 1997; Ali et al., 1998; Ali and Thomson, 1998). In Figure 1C, we call these latter INs Martinotti-like cells (MLCs), although they may in actuality be a combination of SOM and CCK positive INs (Hefft and Jonas, 2005; Glickfeld and Scanziani, 2006), thus potentially making the hippocampal scenario more complex than the neocortical one (Figure 1A). Regardless, during high frequency spiking in CA1 PCs, this leads to early-onset firing in some INs and late onset in others. Because the former innervate PCs perisomatically whereas the latter predominantly target the apical dendrite (Figure 1C), this leads to temporal information being remapped spatially across the somato-dendritic axis (Pouille and Scanziani, 2004), as seen in neocortex and cerebellum. Additionally, earlyonset INs may also inhibit late-onset INs (Lovett-Barron et al., 2012), accentuating further the temporal difference in firing.

These findings suggest that postsynaptic cell type can determine presynaptic terminal properties. Sylwestrak and Ghosh (2012) recently identified a candidate transsynaptic regulator gene, Elfn1, which was expressed preferentially in SOM-positive oriens lacunosum-moleculare (OLM) INs and that may signal postsynaptic identity to presynaptic terminals. Knockdown of Elfn 1 in OLM INs led to a marked reduction in facilitation and in an increase of $p_{\text {release }}$ at connections from CA1 PCs, an effect 
not seen in uninfected neighbor cells (Figure 2). Conversely, overexpression of Elfn 1 in PV INs converted its short-term depressing CA1 PC inputs to facilitation (Figure 2) (Sylwestrak and Ghosh, 2012), suggesting that Elfn 1 controls whether a synapse is facilitating or depressing. Mechanistically, Elfn1 may promote facilitation via synapse-specific presynaptic GluR6 expression, because GluR6 kainate receptor blockade reduced facilitation at PC to OLM IN synapses, but less so at connections to Elfn 1 knockdown neurons (Figure 2) (Sylwestrak and Ghosh, 2012).

Other hippocampal connections show more varied targetspecific STP. For example, synapses from CA3 PCs to CA1 stratum oriens (SO) INs exhibit greater facilitation than those to CA1 PCs (Hampson et al., 1998). Additionally, CA3 PC terminals contacting mGluR1a-positive SO INs express high levels of mGluR7 (Shigemoto et al., 1996) that selectively decrease transmitter release at these synapses (Scanziani et al., 1998). In contrast, (Sun et al., 2005) observed that connections from CA3 PCs to stratum radiatum (SR) INs had less facilitation or even depression. Presynaptic terminal properties can thus differ widely depending on the target cell, even across IN types. Properly determining IN class is therefore vital when investigating target-specific STP (Ascoli et al., 2008; DeFelipe et al., 2013).

In CA3, large boutons of mossy fibers originating from granule cells in the dentate gyrus contact PCs, whilst smaller synapses impinge on INs (Acsady et al., 1998). Synapses onto CA3 PCs have many release sites with low prelease, resulting in facilitation. Synapses onto CA3 INs, however, are less facilitating, or can be depressing (Salin et al., 1996; Toth et al., 2000). The balance of excitation and inhibition furthermore depends on frequency: excitatory drive of INs depresses more rapidly at high frequencies, while that onto PCs does not (Mori et al., 2004). Dentate gyrus granule cells firing at low frequencies thus prioritises inhibition, whilst higher frequencies excite postsynaptic PCs. Together, these features may explain high-frequency burst firing in CA3 PCs as an animal enters a place field (Leutgeb et al., 2007). Facilitation at mossy fiber to CA3 PC synapses may additionally rely on presynaptic kainate receptors (Darstein et al., 2003; Scott et al., 2008; Ruiz and Kullmann, 2012) that cause facilitation of presynaptic calcium entry.

Whilst the studies above often describe STP between excitatory cells, target-specificity has usually been established only by comparison to connections onto inhibitory interneurons. Target-specific STP at different excitatory-excitatory connections is therefore an interesting possibility that has been investigated in less detail, perhaps as the recordings required for direct comparison are more difficult to achieve experimentally. This said, some studies have touched on this topic. In neocortex, stellate cells in layer 4 connect with depressing synapses (Egger et al., 1999), similarly to synapses between L4 and L2/3 (Brasier and Feldman, 2008). Hippocampal mossy fiber synapses onto mossy cells in the dentate gyrus exhibit facilitation, as do mossy fiber-CA3 PC synapses (Lysetskiy et al., 2005). Cerebellar mossy fibers synapse on both deep cerebellar nuclei and granule cells with short-term depressing connections (Saviane and Silver, 2006; Zhang and Linden, 2006). Whilst the evidence above seems to suggest less difference between STP onto excitatory cells, there is still the possibility of more subtle differences, similar to those seen between PC-PC and PC-BC connections in visual cortex (Costa et al., 2013). Revealing subtle differences at connections between excitatory neurons may thus require more refined experimental and theoretical techniques (Costa et al., 2013).

\section{CANDIDATE MOLECULES FOR TARGET-CELL-SPECIFIC RETROGRADE SIGNALLING}

Target-cell-specific STP predicts that neighboring presynaptic compartments may possess dissimilar release properties, as
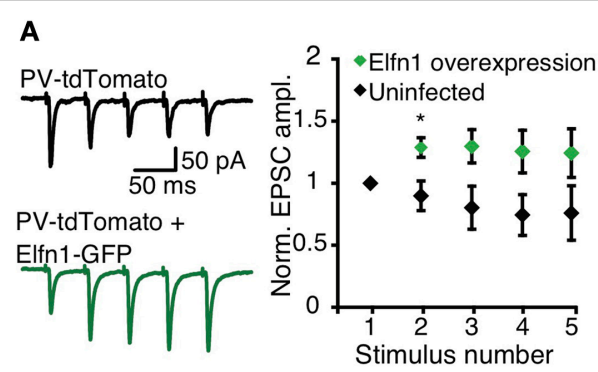
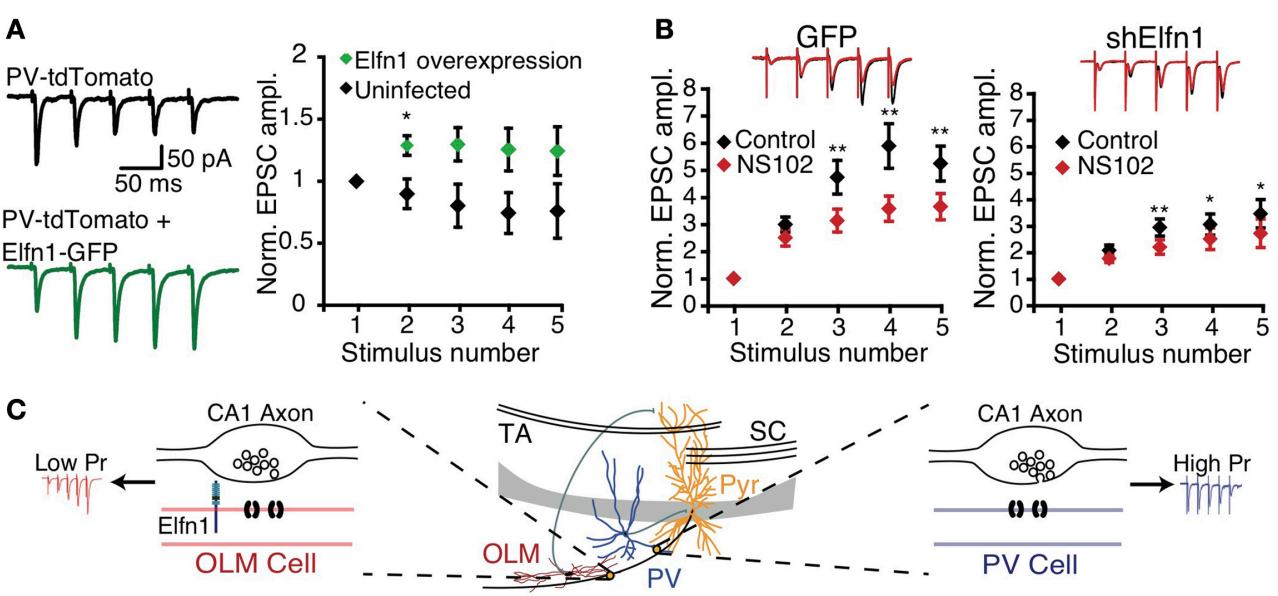

FIGURE 2 | Postsynaptic Elfn1 controls presynaptic transmitter release. (A) Five stimuli at $20 \mathrm{~Hz}$ in the alveus produce short-term depression in stratum pyramidale or oriens PV INs (black). PV neurons overexpressing Elfn1-GFP no longer short-term depress (green). Left: example traces, right: ensemble normalized EPSC amplitude. (B) SOM INs normally facilitate (black), but facilitation is attenuated by GluR6-selective kainate receptor antagonist NS102 (left, red, $n=8$ ). ShElfn1 expression reduces NS102 effect (right, $n=14$ ). Top: example responses, bottom: ensemble normalized EPSC amplitude. (C) Proposed Elfn1 mechanism: CA1 PCs contact PV (blue) and SOM (red) INs (middle). PC synapses onto PV neurons lacking Elfn1 have short-term depression (blue). However, SOM INs expressing Elfn1 transsynaptically reduce probability of release, leading to facilitating PC-SOM IN connections (red). From (Sylwestrak and Ghosh, 2012). Reprinted with permission from AAAS. (A) $* P<0.05$ by Mann-Whitney $U$ test. (B) ${ }^{*} P<0.05 ;{ }^{* *} P<0.01$ by ANOVA with Tukey's post-hoc test. 
governed by their postsynaptic partners (see Figure 1). This scenario requires that the postsynaptic cell can regulate specifically its own presynaptic compartment by retrograde signaling without affecting neighboring presynaptic compartments that synapse onto other cell types (Sylwestrak and Ghosh, 2012). Once a synapse has formed, diffusible retrograde messengers such as endocannabinoids and nitric oxide (Kreitzer and Regehr, 2002; Regehr et al., 2009) thus do not appear to be the most parsimonious players in target-cell-dependent synaptic dynamics, since these render micrometer-scale synapse specificity difficult to achieve. However, several synaptic adhesion molecules enable specific retrograde regulation of presynaptic compartments (see Table 1). Although their involvement in target-cell-specific retrograde signaling per se remains to be shown, they constitute appealing candidates.

Cadherins are a group of synaptic adhesion molecules widely believed to be involved in e.g., synapse formation (Takeichi and Abe, 2005; Takeichi, 2007). To establish transsynaptic interactions, postsynaptic cadherins bind to the extracellular domain of the same type of cadherins located in the presynaptic terminal. These molecules appear to have an important role in mediating synaptic plasticity and to control $p_{\text {release. In a study }}$ by Bozdagi et al. (2004), postsynaptic blockade of N-cadherin, a cadherin molecule expressed at excitatory synapses, lead to smaller synapses, decreased vesicle recycling, and lowered $p_{\text {release }}$. Another study, in this case using presynaptic wild-type neocortical neurons paired with embryonic stem cells lacking N-cadherin, showed enhanced short-term depression in response to $50-\mathrm{Hz}$ stimulation (Jungling et al., 2006). In some stimulation conditions, however, absence of $\mathrm{N}$-cadherin surprisingly converted short-term depression to facilitation. The amplitude of the first response of a train was not altered, indicating that the initial release probability was unaffected. This implies a deficiency in maintaining transmitter release probability, causing a synaptic depression. The authors concluded that the reduced release probability was caused by an altered rate of recruitment to the readily releasable vesicle pool. In a more recent study, N-cadherin deletion reduced the total number of vesicles as well as the number of docked vesicles, thereby reducing prelease (Vitureira et al., 2012). However, no change in calcium sensitivity was seen. The study also shows that the GluA2 subunit can act as a possible mediator of the effect of $\mathrm{N}$-cadherins. Taken together, these three studies suggest a key role for $\mathrm{N}$-cadherins in governing the dynamics of glutamatergic neurotransmission.

Neuroligins, another group of postsynaptic cell adhesion proteins with a role in synapse maturation, has also been implicated in transsynaptic regulation of neurotransmitter release (Dean and Dresbach, 2006). Neuroligins bind to several proteins in the postsynaptic structure such as PSD-95, but also to neurexins, which are membrane surface proteins located in the presynaptic terminal. Neurexins recruit a series of proteins involved in the presynaptic release machinery. Neuroligins can thus via neurexins interact with presynaptic calcium channels, synaptic vesicles, and other release-related proteins (Dean and Dresbach, 2006). In one study, deletion of neuroligins reduced the frequency of both excitatory and inhibitory spontaneous release in respiratory neurons of the brain stem as a direct consequence of reduced $p_{\text {release }}$ (Varoqueaux et al., 2006), showing that neuroligins are essential for proper presynaptic function. Neuroligins were not, however, necessary for synapse numbers, although synaptic maturation was perturbed (Varoqueaux et al., 2006). Another study showed that the recycling vesicle pool size as well as the frequency of spontaneous excitatory release increased when neuroligin 1 was overexpressed, while its deletion resulted in immature presynaptic terminals and a diminished vesicle pool size (Wittenmayer et al., 2009). Neuroligins bind to PSD95 postsynaptically, which has previously been shown to accelerate synaptic maturation (El-Husseini et al., 2000). To explore this interaction further, Futai et al. (2007) studied its potential role in regulating prelease. Overexpression of PSD95 or neuroligins reduced paired-pulse ratio, while deletion of the same proteins increased paired-pulse ratio, indicating that either PSD95 or neuroligins can increase prelease. The effect of up-regulating one of the proteins was occluded by down-regulating the other. Overexpression resulted in increased sensitivity to extracellular calcium concentration and in higher glutamate concentration in the synaptic cleft, indicating

Table 1 | Postsynaptic molecules governing presynaptic transmitter release.

\begin{tabular}{|c|c|c|c|c|c|}
\hline Brain region & Protein & $\mathbf{P}_{\text {rel }}$ & $\mathbf{P}_{\text {ves }}$ & RRP & References \\
\hline Hippocampus* & N-cadherin & + & $?$ & + & Bozdagi et al., 2004 \\
\hline Embryonic stem cells & $\mathrm{N}$-cadherin & + & $x$ & + & Jungling et al., 2006 \\
\hline Brain stem $\#$ & Neuroligin & + & $?$ & $?$ & Varoqueaux et al., 2006 \\
\hline Hippocampus* & Neuroligin & + & $?$ & + & Wittenmayer et al., 2009 \\
\hline Hippocampus* & SynCAM & + & $?$ & $?$ & Sara et al., 2005 \\
\hline Hippocampus* & SAP97 & + & $?$ & + & Regalado et al., 2006 \\
\hline Hippocampus* & PSD95 & + & $?$ & $?$ & El-Husseini et al., 2000 \\
\hline Hippocampus* & SHANK1 & + & $?$ & + & Sala et al., 2001 \\
\hline
\end{tabular}

$P_{\text {rel, }}$, release probability; $P_{\text {ves, }}$ vesicular release probability; $R R P$, readily releasable pool; ${ }^{*}$, dissociated cell culture; 0 , organotypic slices; ${ }^{\prime}$, acute slices; + , the protein has positive effect; $X$, the protein has no effect; ?, effect of the protein was not investigated. 
that more vesicles were released. The effect on release was mediated by presynaptic $\beta$-neurexins (Futai et al., 2007). To conclude, neuroligins are well suited for regulating $p_{\text {release, }}$ possibly by controlling both the vesicle pool size and the calcium sensitivity. In addition to their individual effects on transmitter release, the cadherin and neuroligin systems can cooperate in regulating release from presynaptic terminals. Stan et al. (2010) found that $\mathrm{N}$-cadherin caused neuroligin to accumulate postsynaptically and that it also activated neuroligin via S-SCAM, a scaffolding molecule, which in turn led to clustering of presynaptic vesicles. Hence, $\mathrm{N}$-cadherin is required for neuroligin to increase $p_{\text {release. }}$.

There are several other molecules that have been suggested to play a part in transsynaptic regulation of presynaptic transmitter release via activation of either the neuroligin or the cadherin system. One example is SynCAM, an immunoglobulin domain-containing homophilic synaptic cell adhesion molecule, that when overexpressed in hippocampal neurons brings about an increase in excitatory spontaneous release (Biederer et al., 2002; Sara et al., 2005). Likewise, overexpression of SAP97, a postsynaptic scaffolding protein, increased vesicle release probability, presynaptic protein content, and the size of the active zone (Regalado et al., 2006). Overexpression of Shank1, a synaptic scaffolding protein implicated in autism (Jiang and Ehlers, 2013), has been shown to enhance spontaneous excitatory release and the vesicle pool size (Sala et al., 2001).

\section{TARGET-SPECIFIC CONTROL OF TRANSMITTER RELEASE BY PRESYNAPTIC IONOTROPIC RECEPTORS}

The above synaptic adhesion molecules may enable cells to signal specifically to their own presynaptic boutons. The regulation of neurotransmitter release could subsequently be achieved via many different presynaptic mechanisms (reviewed in Zucker and Regehr, 2002; Thomson, 2003; Fioravante and Regehr, 2011), e.g., by controlling the calcium buffer calbindin-D28k (Blatow et al., 2003) or vesicle-priming RIM proteins (Deng et al., 2011a; Han et al., 2011).

In the past decade, attention has turned to presynaptic ionotropic receptors in synapse-specific control of transmitter release (Engelman and MacDermott, 2004). Presynaptic kainate receptors, for example, act as autoreceptors to promote facilitation at Schaffer collateral synapses to CA1 INs but not to CA1 PCs (Sun and Dobrunz, 2006). During high-frequency firing, cerebellar PF synapses onto stellate INs are depressed by presynaptic kainate autoreceptors, while synapses to Purkinje cells are enhanced (Delaney and Jahr, 2002). Probability of release at connections between molecular-layer INs, on the other hand, is increased by calcium-permeable AMPA receptors located in axonal compartments, which are presumably activated by glutamate spillover from nearby PFs (Rossi et al., 2008). Interestingly, no such effect can be observed at connections from molecularlayer INs and Purkinje cells (Rossi et al., 2008), again an example of how the mechanisms that govern synaptic release properties can be determined by the postsynaptic target cell type.

NMDA receptors are tetrameric ionotropic glutamate receptors that have been implicated in memory formation and in disease states such as pain, neurodegeneration and schizophrenia (Paoletti et al., 2013). Interestingly, presynaptically located
NMDA receptors (preNMDARs) upregulate neurotransmitter release in visual cortex (Sjöström et al., 2003) and entorhinal cortex (Berretta and Jones, 1996). However, the very existence of preNMDARs has been highly debated (see Duguid and Sjöström, 2006; Corlew et al., 2008; Duguid, 2012). Several recent studies suggest that preNMDARs are only expressed at certain synapse types, which may help explain the controversy. Brasier and Feldman (2008) showed that neocortical preNMDARs were present at excitatory connections from layer 4 to layer $2 / 3$ enhanced neurotransmission, while they were absent at excitatory connections within those layers. Such synapse specificity may also be present in the cerebellum, where only a subset of excised molecular layer IN axon terminals were found to express NMDARs (Fiszman et al., 2005), an observation supported by laser uncaging at axon terminals resulting in NMDA-mediated currents at only $30 \%$ of locations (Rossi et al., 2012). If the expression of preNMDARs is synapse specific, what role do these receptors play? Our recent results have shed some light on this (Buchanan et al., 2012).

Using NMDA uncaging onto PC axons in combination with paired recordings and pharmacology, we found that in layer 5 of developing visual cortex, preNMDARs are present at connections from PCs to other PCs as well as to MCs, but not to BCs (Figure 3A) (Buchanan et al., 2012). These preNMDARs upregulate $p_{\text {release }}$ during high-frequency firing, such as the layer-5 PC complex spike (Larkum et al., 1999; Murayama et al., 2009). A neuronal network computer model tuned to STP data and intrinsic firing properties predicted that during high frequency bursting in PCs, preNMDARs specifically upregulate disynaptic inhibition mediated by MCs but not BCs (Figure 3B) (Buchanan et al., 2012). Model predictions were verified by experiments showing that preNMDAR blockade reduced MC but not BC inhibition (Figures 3C,D) (Buchanan et al., 2012). In conclusion, synapsespecific preNMDAR expression combines with target-cell-specific STP to remap high-frequency spiking along the somato-dendritic axis of PCs. Because MCs inhibit PC dendrites (Figure 1A), preNMDARs strongly impact both PC spiking output (Larkum et al., 1999; Murayama et al., 2009) and plasticity (Sjöström et al., 2008). Since neocortical preNMDARs are downregulated at the end of the critical period (Corlew et al., 2007), this link to plasticity suggests a possible causal relationship. PreNMDARs were also recently implicated in spreading depression (Zhou et al., 2013), a slowly propagating wave of neuronal depolarization that contributes to pathology resulting from stroke and other central nervous system trauma. Here, preNMDARs may sustain spreading depression via regenerative glutamate release (Zhou et al., 2013), although the link to synapse-specific expression per se is unknown.

\section{STP DEPENDS ON AGE}

Over development, STP switches in several brain regions from high to low probability of release, i.e., from short-term depression to relatively more facilitating short-term dynamics (Bolshakov and Siegelbaum, 1995; Pouzat and Hestrin, 1997; Reyes and Sakmann, 1999; Kumar and Huguenard, 2001; Wasling et al., 2004; Yanagisawa et al., 2004; Zhang, 2004; Frick et al., 2007; Oswald and Reyes, 2008; Cheetham and Fox, 2010; Wang et al., 
A
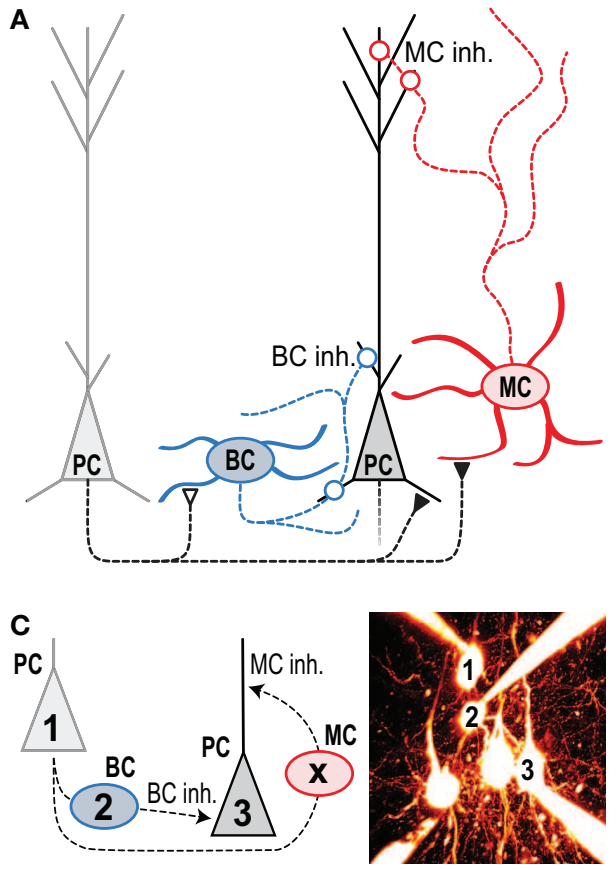

FIGURE 3 | Presynaptic NMDARs reroute spiking in neocortical microcircuits. (A) Presynaptic NMDARs are specifically expressed at PC-PC and PC-MC synapses (closed symbols), but not at the other connections (open symbols). Circles denote inhibitory synapses. (B) A network model with tuned synaptic dynamics predicted that during $70-\mathrm{Hz}$ presynaptic PC firing (vertical lines) blockade of preNMDARs would affect late $M C$ but not early $B C$ inhibition. Traces indicate the model's prediction of synaptic dynamics before (blue) and after (red)

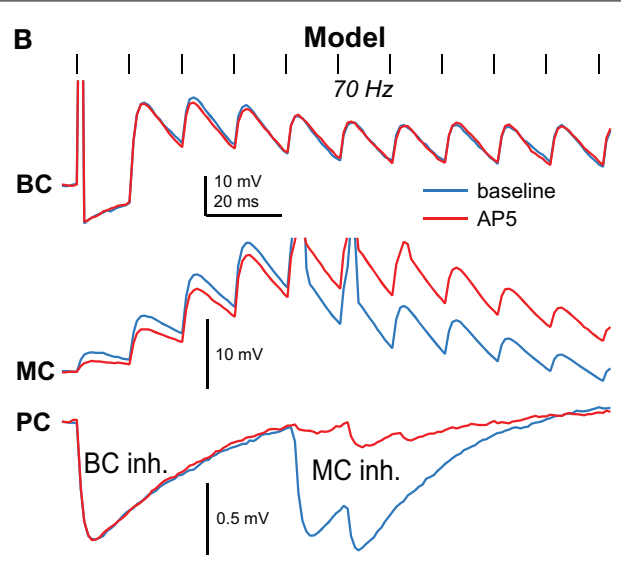

D

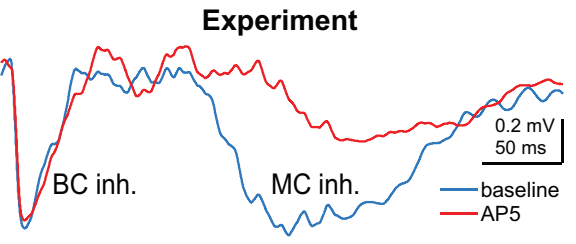

NMDAR blockade with AP5. (C) In this experiment, $70-\mathrm{Hz}$ spiking in cell 1 resulted in both $\mathrm{MC}$ and $\mathrm{BC}$-mediated inhibition in cell 3 when intermediate BC 2 was subthreshold depolarized. Intermediate $M C(X)$ was not patched. (D) As predicted, AP5 wash-in affected the amplitude and latency of $\mathrm{MC}$ but not BC inhibition, indicating that preNMDARs at PC-MC but not PC-BC synapses boost neurotransmission during high-frequency firing. Reproduced from Buchanan et al. (2012) with permission from Elsevier.
2012). This developmental change is likely to be due to maturation of calcium signaling and neurotransmitter release mechanisms in the presynaptic terminal (Zucker and Regehr, 2002). As an example, at the calyx of Held, there is a presynaptic change in voltage-dependent calcium channels at around postnatal day 8 , from $\mathrm{N}$ to $\mathrm{P} / \mathrm{Q}$-type calcium channels (Iwasaki and Takahashi, 1998), which is associated with larger postsynaptic responses and less short-term depression at postnatal day 14 (Iwasaki and Takahashi, 2001). Interestingly, the developmental switch of STP occurs later in visual cortex than in barrel cortex, perhaps because the former develops more slowly (Cheetham and Fox, 2010, 2011), which suggests that sensory experience drives this STP switch. This view, however, is not supported by experiments in neocortical organotypic slice (Chen and Buonomano, 2012), where sensory experience clearly is eliminated, yet the STP switch remains. Perhaps activity of any kind, not necessarily driven by experience, is sufficient. However, Wasling et al. (2004) found that the hippocampal developmental switch in STP persisted even when normal activity levels were dramatically reduced in the second postnatal week by tetanus toxin injection. From these two studies, it seems most parsimonious to conclude that an ontogenetic program governs the developmental STP switch rather than experience-driven plasticity. But several studies are in disagreement and are instead supporting the view that experience and activity is critically needed for this developmental maturation of STP (Finnerty et al., 1999; Tang et al., 2007; Cheetham and Fox, 2010, 2011; Takesian et al., 2010; Liu et al., 2012; Takesian et al., 2013). Whether the shift definitely is experience and activity dependent or not in all brain regions and under all circumstances thus remains an open question.

What is the function of this developmental STP switch? Cheetham and Fox (2010) proposed that in early development strong short-term depression of excitation is necessary to prevent runaway excitation since inhibition is not yet fully mature. In adult animals, however, fully developed inhibition may eliminate this need for strong depression, thus permitting excitatory synapses to express a richer spectrum of short-term dynamics. Interestingly, it has also been suggested that this developmental switch might be related to the critical period (Yanagisawa et al., 2004). Although these are quite plausible propositions, the lack of a substantial amount of data obliges us to conclude that the precise function of this developmental switch remains unknown.

One interesting possibility is that the dynamics of different synapse types may mature in a differential manner. In other words, synapse types with similar STP may become dissimilar with age, while those with different synaptic dynamics in the juvenile state may be indistinguishable as the brain reaches maturity. To our knowledge, this possibility has not been extensively explored. One study by Takesian et al. (2013), however, found 
that thalamic excitation onto fast-spiking INs in gerbil auditory cortex matured toward more short-term depression, whereas the same inputs to low-threshold spiking INs became strikingly facilitating with development. These two types of inputs thus started out with quite similar synaptic dynamics, only to differentiate with age into entirely dissimilar forms of STP. Interestingly, this developmental maturation required activity, since these synapses did not differentiate properly in gerbils with sensorineural hearing loss (Takesian et al., 2013).

\section{CONCLUSIONS AND FUTURE DIRECTIONS}

In this review, we have discussed the functions and mechanisms of STP, with a specific focus on synapse-specific forms of synaptic dynamics. We should point out that, from a naïve and unbiased point of view, there is no a priori theoretical reason to believe that STP ought to be specific to synapse type at all—STP could for example be heterogeneously determined by active learning rules that control synaptic dynamics (Markram and Tsodyks, 1996; Sjöström et al., 2003, 2007), or it could just be random; a form of biological noise. As discussed in this review, however, there are numerous examples of synapse-specific forms of STP. Once such synapse specificity of STP has been discovered, it is perhaps less surprising that this specificity can be determined by the presynaptic neuronal type (e.g., Gupta et al., 2000), since neurotransmitter release itself is typically controlled by presynaptic mechanisms (Zucker and Regehr, 2002; Abbott and Regehr, 2004). The existence of target-cell-specific forms of synaptic dynamics, however, may seem surprising and roundabout, since in this case the postsynaptic cell must signal across the synapse to the presynaptic terminal to determine its properties. The fact that such mechanisms do exist (see above and Sylwestrak and Ghosh, 2012) strongly suggests that these target-specific forms of STP are critically important for the proper functioning of the brain.

An emerging principle is thus that STP must be analyzed and understood in the context of the local circuit. This requires combining different scientific disciplines ranging from molecular biology through electrophysiology to computer modeling. This also critically requires that cell types be properly identified, which itself can be a major challenge (Markram et al., 2004; Ascoli et al., 2008). From a theoretical point of view, this suggests that just adding inhibition to a network model of excitatory neurons to balance activity out may sometimes not be enough or even erroneous, since a common theme for all examples of synapse-specific STP is that the most extreme differences are found with respect to different inhibitory IN types. Adding inhibition of one or another type will therefore strongly impact the spatio-temporal structure of network activity. For example, Krishnamurthy et al. (2012) found that the synapse-specific facilitation of excitation onto MCs can drive cortical attractor networks, a role that BCs could not take on because of short-term depression of their excitatory inputs. In general, we believe that the theory of synapse-specific STP deserves more attention, especially since the functional implications can be very difficult to ascertain experimentally.

Still, it is important to recall that STP can also be directly postsynaptically determined, for example due to desensitization of calcium-permeable AMPA receptors (Rozov and Burnashev,
1999; Rozov et al., 2001). Since calcium-permeable AMPA receptors are also synapse-specifically expressed (Rozov et al., 2001; Kullmann and Lamsa, 2007), these receptors may provide a degree of target-cell-specific STP. Another type of postsynaptically derived STP was found in cerebellar stellate cells, which exhibit a gradient of facilitation decreasing from the soma to distal synapses. Distance-dependent facilitation arises from large synaptic conductances depolarizing thin dendrites so much that driving force is reduced, so responses summate sublinearly. This feature potentially makes stellate cells into decorrelators by favoring distributed, non-clustered input activity (Abrahamsson et al., 2012). In addition, postsynaptic temporal summation can itself result in an apparent form of short-term depression, even for connections that are in actuality somewhat facilitating (Banitt et al., 2005).

But we should re-iterate that the postsynaptic neuron does not solely determine synapse type; target-cell-specific STP is merely the specific focus of this particular review article. Indeed, Gupta et al. (2000) summarized their findings in several circuitorganizing principles, the second of which states that "the postsynaptic neuron alone cannot dictate the type of synapse"accordingly it is still possible for STP to be determined by presynaptic cell type (e.g., Planert et al., 2010). Likewise, plasticity learning rules that impact short-term dynamics (e.g., Markram and Tsodyks, 1996; Sjöström et al., 2003, 2007) are still likely to critically determine computations within a set of synapses of the same type. These three different forms of STP specificitypresynaptic, postsynaptic, or otherwise (e.g., via plasticity)are thus not mutually exclusive, but can co-exist in the brain. Because synaptic plasticity rules may vary with dendritic location (Sjöström and Häusser, 2006; Kampa et al., 2007; Sjöström et al., 2008; Froemke et al., 2010), this suggests that STP may be regulated on a finer grain than individual postsynaptic cells. Via dendritically local synaptic plasticity rules, STP may in fact be determined by postsynaptic compartment (Branco et al., 2008; Branco and Staras, 2009). Indeed, there is evidence that STP depends on dendritic location (Williams and Stuart, 2002; de Jong et al., 2012), in keeping with this idea, although as discussed above, a similar STP gradient may also arise directly from dendrite biophysics (Abrahamsson et al., 2012).

Furthermore, since most synapses seem to undergo developmental switches in STP, as discussed above, this potentially alters the picture of target-specific STP. For example, connections between PCs in neocortex have been observed to change from depressing to facilitating during development (Reyes and Sakmann, 1999), which would with age potentially render them more dissimilar to those between PCs and BCs (see Figure 1A and Buchanan et al., 2012; Costa et al., 2013). However, a similar developmental change from depression to facilitation has been observed at connections between PCs and putative BCs at low but not high frequencies (Angulo et al., 1999). Some forms of targetspecific STP may thus be revealed only by certain activity patterns. And as discussed earlier, Takesian et al. (2013) found that the developmental switch is precisely the opposite for excitation onto fast-spiking compared to low-threshold spiking INs in auditory cortex. These findings thus complicate the picture considerably, which means experimenters must take great care. 
The inhibitory circuits activated by target-specific STP are also subject to modulatory and disinhibitory control. For example, monocular deprivation during a critical period leads to a transient reduction in the activity of PV-specific inhibitory circuits in binocular visual cortex, which is permissive for competitive plasticity and ocular dominance shifts (Kuhlman et al., 2013). Similarly, receptive field plasticity in auditory cortex depends on disinhibition mediated by activation of modulatory cholinergic inputs (Froemke et al., 2007), whilst auditory fear conditioning involves cholinergic activation of layer 1 INs which then inhibit L2/3 PV INs (Letzkus et al., 2011). Interestingly, recent evidence suggests that vasoactive intestinal polypeptide (VIP) expressing INs may specialize in such disinhibition, and target primarily SOM and a subset of PV INs (Pi et al., 2013). Because different IN types have distinct forms of STP, a largely unexplored link between synapse-specific STP and regulation of critical period opening and closure thus beckons.

Forms of plasticity other than STP may also be synapse specific and may thus depend on the postsynaptic cell type. For example, long-term plasticity depends on the target inhibitory cell type in neocortex (Lu et al., 2007) and in hippocampus (Nissen et al., 2010; also see McBain and Kauer, 2009). Homeostatic plasticity in neocortex is also dependent on the synapse type (Bartley et al., 2008). These findings further strengthen the principle that synaptic plasticity in general has to be understood in the context of the local circuit.

Another emerging principle is that late-onset INs target the dendrite of local principal neurons, whereas early-onset INs are perisomatically innervating (see Figure 1). This pattern has been found in several neocortical regions (Silberberg and Markram, 2007; Berger et al., 2009), cerebellum (Bao et al., 2010), and hippocampus (Pouille and Scanziani, 2004). In developing visual cortex, this temporal-to-spatial remapping of early $\mathrm{BC}$ and late MC spiking across the somato-dendritic axis (Figure 1A) is augmented by preNMDARs that maintain PC-MC neurotransmission during high-frequency firing (see Figure 3 and Buchanan et al., 2012). Recent experiments in awake animals suggest that prominent cortical late-onset inhibition may restrict persistence and spatial spread of activity, thus playing a key role in wakefulness and attention (Haider et al., 2012).

Based on a normative theoretical approach, Pfister et al. (2010) found that STP may make postsynaptic neurons optimal estimators of presynaptic membrane potential. Although the existence of target-specific STP might at first appear to be in contradiction to this theory (see Pfister et al., 2010), another more optimistic interpretation is that different neuronal types may compute different presynaptic statistical properties.

An involvement of target-cell specific STP in disability and disease has also emerged recently. For example, the Fragile X Mental Retardation Protein FMRP regulates neurotransmitter release presynaptically (Deng et al., 2013) and Fmr1 gene knockout results in pathological STP (Deng et al., 2011b). But the role of presynaptic Fmr1 is specific to target cell type, dramatically affecting STP at synapses onto fast-spiking INs while leaving STP at connections to excitatory cells untouched (Patel et al., 2013). Because of the increased usage of technologies such as 2-photon imaging and paired recordings, the field of synapse-specific STP has become so refined that neuroscientists are now ready to untangle the specific roles of different synapse types in synaptic diseases such as autism, anxiety and epilepsy (Lüscher and Isaac, 2009).

In this paper, we have overviewed the possible functions and mechanisms of target-specific STP. We have listed several examples of STP specific to the target cell, and we have found a few common principles, but it is clear that not nearly enough is known about the why and the how, which means the specificity of STP should be investigated considerably more, both experimentally and theoretically. We argue that to understand the function of target-specific STP, researchers have to examine the results in the context of the local circuit, with its many different cell and synapse types (e.g., Pouille and Scanziani, 2004; Buchanan et al., 2012). Elucidating the role of target-specific STP is therefore likely to require a combination of tools from molecular biology, advanced optics, multiple-cell electrophysiology, and computer modeling.

\section{ACKNOWLEDGMENTS}

We thank Karri Lamsa, Keith Murai, Alanna Watt, and the Sjöström lab for help and useful discussions. We thank Emily Sylwestrak and Anirvan Ghosh for Figure 2. This work was funded by MRC Career Development Award G0700188 (P. Jesper Sjöström), BBSRC Industrial CASE Award BB/H016600/1 (Arne V. Blackman), Fundação para a Ciência e a Tecnologia (Rui Ponte Costa), the EPSRC (Rui Ponte Costa), EU FP7 Future Emergent Technologies grant \#243914 "Brain-i-nets" (P. Jesper Sjöström), CFI Leaders Opportunity Fund \#28331 (P. Jesper Sjöström), CIHR OG 126137 (P. Jesper Sjöström), and NSERC DG 418546-2 (P. Jesper Sjöström).

\section{REFERENCES}

Abbott, L. F., and Regehr, W. G. (2004). Synaptic computation. Nature 431, 796-803. doi: 10.1038/nature03010

Abbott, L. F., Varela, J. A., Sen, K., and Nelson, S. B. (1997). Synaptic depression and cortical gain control. Science 275, 220-224. doi: 10.1126/science.275.5297.221

Abrahamsson, T., Cathala, L., Matsui, K., Shigemoto, R., and DiGregorio, D. A. (2012). Thin dendrites of cerebellar interneurons confer sublinear synaptic integration and a gradient of short-term plasticity. Neuron 73, 1159-1172. doi: 10.1016/j.neuron.2012.01.027

Acsady, L., Kamondi, A., Sik, A., Freund, T., and Buzsaki, G. (1998). GABAergic cells are the major postsynaptic targets of mossy fibers in the rat hippocampus. J. Neurosci. 18, 3386-3403.

Ali, A. B., Deuchars, J., Pawelzik, H., and Thomson, A. M. (1998). CA1 pyramidal to basket and bistratified cell EPSPs: dual intracellular recordings in rat hippocampal slices. J. Physiol. 507(Pt 1), 201-217. doi: 10.1111/j.1469-7793.1998.201bu.x

Ali, A. B., and Thomson, A. M. (1998). Facilitating pyramid to horizontal oriens-alveus interneurone inputs: dual intracellular recordings in slices of rat hippocampus. J. Physiol. 507(Pt 1), 185-199. doi: 10.1111/j.14697793.1998.185bu.x

Angulo, M. C., Staiger, J. F., Rossier, J., and Audinat, E. (1999). Developmental synaptic changes increase the range of integrative capabilities of an identified excitatory neocortical connection. J. Neurosci. 19, 1566-1576.

Arguello, P. A., and Gogos, J. A. (2012). Genetic and cognitive windows into circuit mechanisms of psychiatric disease. Trends Neurosci. 35, 3-13. doi: 10.1016/j.tins.2011.11.007

Ascoli, G. A., Alonso-Nanclares, L., Anderson, S. A., Barrionuevo, G., BenavidesPiccione, R., Burkhalter, A., et al. (2008). Petilla terminology: nomenclature of features of GABAergic interneurons of the cerebral cortex. Nat. Rev. Neurosci. 9 , 557-568. doi: 10.1038/nrn2402 
Atwood, H. L. (1967). Variation in physiological properties of crustacean motor synapses. Nature 215, 57-58. doi: 10.1038/215057a0

Atwood, H. L., and Bittner, G. D. (1971). Matching of excitatory and inhibitory inputs to crustacean muscle fibers. J. Neurophysiol. 34, 157-170.

Banitt, Y., Martin, K. A., and Segev, I. (2005). Depressed responses of facilitatory synapses. J. Neurophysiol. 94, 865-870. doi: 10.1152/jn.00689.2004

Bao, J., Reim, K., and Sakaba, T. (2010). Target-dependent feedforward inhibition mediated by short-term synaptic plasticity in the cerebellum. J. Neurosci. 30, 8171-8179. doi: 10.1523/JNEUROSCI.0276-10.2010

Bartley, A. F., Huang, Z. J., Huber, K. M., and Gibson, J. R. (2008). Differential activity-dependent, homeostatic plasticity of two neocortical inhibitory circuits. J. Neurophysiol. 100, 1983-1994. doi: 10.1152/jn.90635.2008

Beierlein, M., Fioravante, D., and Regehr, W. G. (2007). Differential expression of posttetanic potentiation and retrograde signaling mediate target-dependent short-term synaptic plasticity. Neuron 54, 949-959. doi: 10.1016/j.neuron.2007.06.002

Beierlein, M., Gibson, J. R., and Connors, B. W. (2003). Two dynamically distinct inhibitory networks in layer 4 of the neocortex. J. Neurophysiol. 90, 2987-3000. doi: 10.1152/jn.00283.2003

Berger, T. K., Perin, R., Silberberg, G., and Markram, H. (2009). Frequencydependent disynaptic inhibition in the pyramidal network - a ubiquitous pathway in the developing rat neocortex. J. Physiol. 587(Pt 22), 5411-5425. doi: 10.1113/jphysiol.2009.176552

Berger, T. K., Silberberg, G., Perin, R., and Markram, H. (2010). Brief bursts self-inhibit and correlate the pyramidal network. PLoS Biol. 8:e1000473. doi: 10.1371/journal.pbio.1000473

Berretta, N., and Jones, R. S. (1996). Tonic facilitation of glutamate release by presynaptic $\mathrm{N}$-methyl-D-aspartate autoreceptors in the entorhinal cortex. Neuroscience 75, 339-344. doi: 10.1016/0306-4522 (96)00301-6

Biederer, T., Sara, Y., Mozhayeva, M., Atasoy, D., Liu, X., Kavalali, E. T., et al. (2002). SynCAM, a synaptic adhesion molecule that drives synapse assembly. Science 297, 1525-1531. doi: 10.1126/science. 1072356

Blatow, M., Caputi, A., Burnashev, N., Monyer, H., and Rozov, A. (2003). $\mathrm{Ca} 2+$ buffer saturation underlies paired pulse facilitation in calbindinD28k-containing terminals. Neuron 38, 79-88. doi: 10.1016/S0896-6273 (03)00196-X

Bolshakov, V. Y., and Siegelbaum, S. A. (1995). Regulation of hippocampal transmitter release during development and long-term potentiation. Science 269, 1730-1734. doi: 10.1126/science.7569903

Bozdagi, O., Valcin, M., Poskanzer, K., Tanaka, H., and Benson, D. L. (2004). Temporally distinct demands for classic cadherins in synapse formation and maturation. Mol. Cell. Neurosci. 27, 509-521. doi: 10.1016/j.mcn.2004.08.008

Branco, T., and Staras, K. (2009). The probability of neurotransmitter release: variability and feedback control at single synapses. Nat. Rev. Neurosci. 10, 373-383. doi: $10.1038 / \mathrm{nrn} 2634$

Branco, T., Staras, K., Darcy, K. J., and Goda, Y. (2008). Local dendritic activity sets release probability at hippocampal synapses. Neuron $59,475-485$. doi: 10.1016/j.neuron.2008.07.006

Brasier, D. J., and Feldman, D. E. (2008). Synapse-specific expression of functional presynaptic NMDA receptors in rat somatosensory cortex. J. Neurosci. 28, 2199-2211. doi: 10.1523/JNEUROSCI.3915-07.2008

Buchanan, K. A., Blackman, A. V., Moreau, A. W., Elgar, D., Costa, R. P., Lalanne, T., et al. (2012). Target-specific expression of presynaptic NMDA receptors in neocortical microcircuits. Neuron 75, 451-466. doi: 10.1016/j.neuron.2012.06.017

Chadderton, P., Margrie, T. W., and Häusser, M. (2004). Integration of quanta in cerebellar granule cells during sensory processing. Nature 428, 856-860. doi: 10.1038/nature02442

Chance, F. S., and Abbott, L. F. (2001). Input-specific adaptation in complex cells through synaptic depression. Neurocomputing 141-146. doi: 10.1016/S09252312(01)00550-1

Chance, F. S., Nelson, S. B., and Abbott, L. F. (1998). Synaptic depression and the temporal response characteristics of V1 cells. J. Neurosci. 18, 4785-4799.

Cheetham, C. E., and Fox, K. (2010). Presynaptic development at L4 to 12/3 excitatory synapses follows different time courses in visual and somatosensory cortex. J. Neurosci. 30, 12566-12571. doi: 10.1523/JNEUROSCI.2544-10.2010

Cheetham, C. E., and Fox, K. (2011). The role of sensory experience in presynaptic development is cortical area specific. J. Physiol. 589, 5691-5699. doi: 10.1113/jphysiol.2011.218347
Chen, W. X., and Buonomano, D. V. (2012). Developmental shift of short-term synaptic plasticity in cortical organotypic slices. Neuroscience 213, 38-46. doi: 10.1016/j.neuroscience.2012.04.018

Chung, S., Li, X., and Nelson, S. B. (2002). Short-term depression at thalamocortical synapses contributes to rapid adaptation of cortical sensory responses in vivo. Neuron 34, 437-446. doi: 10.1016/S0896-6273(02)00659-1

Corlew, R., Brasier, D. J., Feldman, D. E., and Philpot, B. D. (2008). Presynaptic NMDA receptors: newly appreciated roles in cortical synaptic function and plasticity. Neuroscientist 14, 609-625. doi: 10.1177/1073858408322675

Corlew, R., Wang, Y., Ghermazien, H., Erisir, A., and Philpot, B. D. (2007). Developmental switch in the contribution of presynaptic and postsynaptic NMDA receptors to long-term depression. J. Neurosci. 27, 9835-9845. doi: 10.1523/JNEUROSCI.5494-06.2007

Costa, R. P., Sjöström, P. J., and van Rossum, M. C. W. (2013). Probabilistic inference of short-term synaptic plasticity in neocortical microcircuits. Front. Comput. Neurosci. 7:75. doi: 10.3389/fncom.2013.00075

Darstein, M., Petralia, R. S., Swanson, G. T., Wenthold, R. J., and Heinemann, S. F. (2003). Distribution of kainate receptor subunits at hippocampal mossy fiber synapses. J. Neurosci. 23, 8013-8019.

de Jong, A. P., Schmitz, S. K., Toonen, R. F., and Verhage, M. (2012). Dendritic position is a major determinant of presynaptic strength. J. Cell Biol. 197, 327-337. doi: $10.1083 /$ jcb. 201112135

Dean, C., and Dresbach, T. (2006). Neuroligins and neurexins: linking cell adhesion, synapse formation and cognitive function. Trends Neurosci. 29, 21-29. doi: 10.1016/j.tins.2005.11.003

DeFelipe, J., Lopez-Cruz, P. L., Benavides-Piccione, R., Bielza, C., Larranaga, P., Anderson, S., et al. (2013). New insights into the classification and nomenclature of cortical GABAergic interneurons. Nat. Rev. Neurosci. 14, 202-216. doi: $10.1038 /$ nrn3444

Delaney, A. J., and Jahr, C. E. (2002). Kainate receptors differentially regulate release at two parallel fiber synapses. Neuron 36, 475-482. doi: 10.1016/S08966273(02)01008-5

Deng, L., Kaeser, P. S., Xu, W., and Sudhof, T. C. (2011a). RIM proteins activate vesicle priming by reversing autoinhibitory homodimerization of Munc13. Neuron 69, 317-331. doi: 10.1016/j.neuron.2011.01.005

Deng, P. Y., Sojka, D., and Klyachko, V. A. (2011b). Abnormal presynaptic shortterm plasticity and information processing in a mouse model of fragile $\mathrm{X}$ syndrome. J. Neurosci. 31, 10971-10982. doi: 10.1523/JNEUROSCI.2021-11.2011

Deng, P. Y., Rotman, Z., Blundon, J. A., Cho, Y., Cui, J., Cavalli, V., et al. (2013). FMRP regulates neurotransmitter release and synaptic information transmission by modulating action potential duration via BK channels. Neuron 77, 696-711. doi: 10.1016/j.neuron.2012.12.018

Dittman, J. S., Kreitzer, A. C., and Regehr, W. G. (2000). Interplay between facilitation, depression, and residual calcium at three presynaptic terminals. J. Neurosci. 20, 1374-1385.

Duguid, I., and Sjöström, P. J. (2006). Novel presynaptic mechanisms for coincidence detection in synaptic plasticity. Curr. Opin. Neurobiol. 16, 312-322. doi: 10.1016/j.conb.2006.05.008

Duguid, I. C. (2012). Presynaptic NMDA receptors: are they dendritic receptors in disguise? Brain Res. Bull. 93, 4-9. doi: 10.1016/j.brainresbull.2012.12.004

Egger, V., Feldmeyer, D., and Sakmann, B. (1999). Coincidence detection and changes of synaptic efficacy in spiny stellate neurons in rat barrel cortex. Nat. Neurosci. 2, 1098-1105. doi: 10.1038/16026

El-Husseini, A. E., Schnell, E., Chetkovich, D. M., Nicoll, R. A., and Bredt, D. S. (2000). PSD-95 involvement in maturation of excitatory synapses. Science 290, 1364-1368. doi: 10.1126/science.290.5495.1364

Engelman, H. S., and MacDermott, A. B. (2004). Presynaptic ionotropic receptors and control of transmitter release. Nat. Rev. Neurosci. 5, 135-145. doi $10.1038 / \mathrm{nrn} 1297$

Fenelon, K., Mukai, J., Xu, B., Hsu, P. K., Drew, L. J., Karayiorgou, M., et al. (2011). Deficiency of Dgcr8, a gene disrupted by the 22q11.2 microdeletion, results in altered short-term plasticity in the prefrontal cortex. Proc. Natl. Acad. Sci. U.S.A. 108, 4447-4452. doi: 10.1073/pnas.1101219108

Finnerty, G. T., Roberts, L. S., and Connors, B. W. (1999). Sensory experience modifies the short-term dynamics of neocortical synapses. Nature 400, 367-371. doi: $10.1038 / 22553$

Fioravante, D., and Regehr, W. G. (2011). Short-term forms of presynaptic plasticity. Curr. Opin. Neurobiol. 21, 269-274. doi: 10.1016/j.conb.2011. 02.003 
Fiszman, M. L., Barberis, A., Lu, C., Fu, Z., Erdelyi, F., Szabo, G., et al. (2005). NMDA receptors increase the size of GABAergic terminals and enhance GABA release. J. Neurosci. 25, 2024-2031. doi: 10.1523/JNEUROSCI.498004.2005

Fortune, E. S., and Rose, G. J. (2001). Short-term synaptic plasticity as a temporal filter. Trends Neurosci. 24, 381-385. doi: 10.1016/S0166-2236(00)01835-X

Frick, A., Feldmeyer, D., and Sakmann, B. (2007). Postnatal development of synaptic transmission in local networks of L5A pyramidal neurons in rat somatosensory cortex. J. Physiol. 585, 103-116. doi: 10.1113/jphysiol.2007.141788

Froemke, R. C., Letzkus, J. J., Kampa, B. M., Hang, G. B., and Stuart, G. J. (2010). Dendritic synapse location and neocortical spike-timing-dependent plasticity. Front. Synaptic Neurosci. 2:29. doi: 10.3389/fnsyn.2010.00029

Froemke, R. C., Merzenich, M. M., and Schreiner, C. E. (2007). A synaptic memory trace for cortical receptive field plasticity. Nature 450, 425-429. doi: 10.1038 /nature06289

Fuhrmann, G., Segev, I., Markram, H., and Tsodyks, M. (2002). Coding of temporal information by activity-dependent synapses. J. Neurophysiol. 87, 140-148. doi: $10.3389 /$ fnsyn.2010.00029

Futai, K., Kim, M. J., Hashikawa, T., Scheiffele, P., Sheng, M., and Hayashi, Y. (2007). Retrograde modulation of presynaptic release probability through signaling mediated by PSD-95-neuroligin. Nat. Neurosci. 10, 186-195. doi: $10.1038 / \mathrm{nn} 1837$

Galarreta, M., and Hestrin, S. (1998). Frequency-dependent synaptic depression and the balance of excitation and inhibition in the neocortex. Nat. Neurosci. 1, 587-594. doi: 10.1038/2882

Glickfeld, L. L., and Scanziani, M. (2006). Distinct timing in the activity of cannabinoid-sensitive and cannabinoid-insensitive basket cells. Nat. Neurosci. 9, 807-815. doi: 10.1038/nn1688

Goldman, M. S., Nelson, S. B., and Abbott, L. F. (1999). Decorrelation of spike trains by synaptic depression. Neurocomputing 147-153. doi: 10.1016/S09252312(99)00068-5

Goldman-Rakic, P. S. (1995). Cellular basis of working memory. Neuron 14, 477-485. doi: 10.1016/0896-6273(95)90304-6

Gupta, A., Wang, Y., and Markram, H. (2000). Organizing principles for a diversity of GABAergic interneurons and synapses in the neocortex. Science 287, 273-278. doi: 10.1126/science.287.5451.273

Haider, B., Häusser, M., and Carandini, M. (2012). Inhibition dominates sensory responses in the awake cortex. Nature 493, 97-100. doi: 10.1038/nature 11665

Hampson, A. J., Bornheim, L. M., Scanziani, M., Yost, C. S., Gray, A. T., Hansen, B. M., et al. (1998). Dual effects of anandamide on NMDA receptormediated responses and neurotransmission. J. Neurochem. 70, 671-676. doi: 10.1046/j.1471-4159.1998.70020671.x

Han, Y., Kaeser, P. S., Sudhof, T. C., and Schneggenburger, R. (2011). RIM determines $\mathrm{Ca}(2)+$ channel density and vesicle docking at the presynaptic active zone. Neuron 69, 304-316. doi: 10.1016/j.neuron.2010.12.014

Hansel, D., and Mato, G. (2013). Short-term plasticity explains irregular persistent activity in working memory tasks. J. Neurosci. 33, 133-149. doi: 10.1523/JNEUROSCI.3455-12.2013

Hebb, D. O. (1949). The Organization of Behavior. New York, NY: Wiley.

Hefft, S., and Jonas, P. (2005). Asynchronous GABA release generates longlasting inhibition at a hippocampal interneuron-principal neuron synapse. Nat. Neurosci. 8, 1319-1328. doi: 10.1038/nn1542

Hempel, C. M., Hartman, K. H., Wang, X. J., Turrigiano, G. G., and Nelson, S. B. (2000). Multiple forms of short-term plasticity at excitatory synapses in rat medial prefrontal cortex. J. Neurophysiol. 83, 3031-3041.

Iwasaki, S., and Takahashi, T. (1998). Developmental changes in calcium channel types mediating synaptic transmission in rat auditory brainstem. J. Physiol. 509(Pt 2), 419-423. doi: 10.1111/j.1469-7793.1998.419bn.x

Iwasaki, S., and Takahashi, T. (2001). Developmental regulation of transmitter release at the calyx of Held in rat auditory brainstem. J. Physiol. 534, 861-871. doi: 10.1111/j.1469-7793.2001.00861.x

Jiang, Y. H., and Ehlers, M. D. (2013). Modeling autism by SHANK Gene mutations in mice. Neuron 78, 8-27. doi: 10.1016/j.neuron.2013.03.016

Jungling, K., Eulenburg, V., Moore, R., Kemler, R., Lessmann, V., and Gottmann, K. (2006). N-cadherin transsynaptically regulates short-term plasticity at glutamatergic synapses in embryonic stem cell-derived neurons. J. Neurosci. 26, 6968-6978. doi: 10.1523/JNEUROSCI.1013-06.2006
Kampa, B. M., Letzkus, J. J., and Stuart, G. J. (2007). Dendritic mechanisms controlling spike-timing-dependent synaptic plasticity. Trends Neurosci. 30, 456-463. doi: 10.1016/j.tins.2007.06.010

Klyachko, V. A., and Stevens, C. F. (2006). Excitatory and feed-forward inhibitory hippocampal synapses work synergistically as an adaptive filter of natural spike trains. PLoS Biol. 4:e207. doi: 10.1371/journal.pbio.0040207

Koester, H. J., and Johnston, D. (2005). Target cell-dependent normalization of transmitter release at neocortical synapses. Science 308, 863-866. doi: 10.1126/science. 1100815

Kreitzer, A. C., and Regehr, W. G. (2002). Retrograde signaling by endocannabinoids. Curr. Opin. Neurobiol. 12, 324-330. doi: 10.1016/S0959-4388(02)00328-8

Krishnamurthy, P., Silberberg, G., and Lansner, A. (2012). A cortical attractor network with Martinotti cells driven by facilitating synapses. PLoS ONE 7:e30752. doi: 10.1371/journal.pone.0030752

Kuhlman, S. J., Olivas, N. D., Tring, E., Ikrar, T., Xu, X., and Trachtenberg, J. T. (2013). A disinhibitory microcircuit initiates critical-period plasticity in the visual cortex. Nature 501, 543-546. doi: 10.1038/nature12485

Kullmann, D. M., and Lamsa, K. P. (2007). Long-term synaptic plasticity in hippocampal interneurons. Nat. Rev. Neurosci. 8, 687-699. doi: 10.1038/nrn2207

Kumar, S. S., and Huguenard, J. R. (2001). Properties of excitatory synaptic connections mediated by the corpus callosum in the developing rat neocortex. J. Neurophysiol. 86, 2973-2985.

Larkum, M. E., Zhu, J. J., and Sakmann, B. (1999). A new cellular mechanism for coupling inputs arriving at different cortical layers. Nature 398, 338-341. doi: $10.1038 / 18686$

Letzkus, J. J., Wolff, S. B., Meyer, E. M., Tovote, P., Courtin, J., Herry, C., et al. (2011). A disinhibitory microcircuit for associative fear learning in the auditory cortex. Nature 480, 331-335. doi: 10.1038/nature10674

Leutgeb, J. K., Leutgeb, S., Moser, M. B., and Moser, E. I. (2007). Pattern separation in the dentate gyrus and CA3 of the hippocampus. Science 315, 961-966. doi: $10.1126 /$ science. 1135801

Lisman, J. E. (1997). Bursts as a unit of neural information: making unreliable synapses reliable. Trends Neurosci. 20, 38-43. doi: 10.1016/S01662236(96)10070-9

Liu, Y., Shi, X., Li, Y., and Zhao, K. (2012). The influences of dark rearing on the transmission characteristics of layer II/III pyramidal cells during the critical period. Brain Res. 1457, 26-32. doi: 10.1016/j.brainres.2012. 03.062

Lovett-Barron, M., Turi, G. F., Kaifosh, P., Lee, P. H., Bolze, F., Sun, X. H., et al. (2012). Regulation of neuronal input transformations by tunable dendritic inhibition. Nat. Neurosci. 15, 423-430, S421-423. doi: 10.1038/nn.3024

Lu, J. T., Li, C. Y., Zhao, J. P., Poo, M. M., and Zhang, X. H. (2007). Spiketiming-dependent plasticity of neocortical excitatory synapses on inhibitory interneurons depends on target cell type. J. Neurosci. 27, 9711-9720. doi: 10.1523/JNEUROSCI.2513-07.2007

Lüscher, C., and Isaac, J. T. (2009). The synapse: center stage for many brain diseases. J. Physiol. 587, 727-729. doi: 10.1113/jphysiol.2008.167742

Lysetskiy, M., Foldy, C., and Soltesz, I. (2005). Long- and short-term plasticity at mossy fiber synapses on mossy cells in the rat dentate gyrus. Hippocampus 15 , 691-696. doi: 10.1002/hipo.20096

Maass, W., and Zador, A. M. (1999). Dynamic stochastic synapses as computational units. Neural Comput. 903-917. doi: 10.1162/089976699300016494

MacLeod, K. M. (2011). Short-term synaptic plasticity and intensity coding. Hear. Res. 279, 13-21. doi: 10.1016/j.heares.2011.03.001

Markram, H., Gerstner, W., and Sjöström, P. J. (2011). A history of spike-timing-dependent plasticity. Front. Synaptic Neurosci. 3, 1-24. doi: 10.3389/fnsyn.2011.00004

Markram, H., Toledo-Rodriguez, M., Wang, Y., Gupta, A., Silberberg, G., and Wu, C. (2004). Interneurons of the neocortical inhibitory system. Nat. Rev. Neurosci. 5, 793-807. doi: 10.1038/nrn1519

Markram, H., and Tsodyks, M. (1996). Redistribution of synaptic efficacy between neocortical pyramidal neurons. Nature 382, 807-810. doi: 10.1038/ $382807 \mathrm{a} 0$

Markram, H., Wang, Y., and Tsodyks, M. (1998). Differential signaling via the same axon of neocortical pyramidal neurons. Proc. Natl. Acad. Sci. U.S.A. 95, 5323-5328. doi: 10.1073/pnas.95.9.5323

Matveev, V., and Wang, X. J. (2000). Differential short-term synaptic plasticity and transmission of complex spike trains: to depress or to facilitate? Cereb. Cortex 10, 1143-1153. doi: 10.1093/cercor/10.11.1143 
McBain, C. J., and Kauer, J. A. (2009). Presynaptic plasticity: targeted control of inhibitory networks. Curr. Opin. Neurobiol. 19, 254-262. doi: 10.1016/j.conb.2009.05.008

Mongillo, G., Barak, O., and Tsodyks, M. (2008). Synaptic theory of working memory. Science 319, 1543-1546. doi: 10.1126/science.1150769

Mori, M., Abegg, M. H., Gahwiler, B. H., and Gerber, U. (2004). A frequencydependent switch from inhibition to excitation in a hippocampal unitary circuit. Nature 431, 453-456. doi: 10.1038/nature02854

Murayama, M., Perez-Garci, E., Nevian, T., Bock, T., Senn, W., and Larkum, M. E. (2009). Dendritic encoding of sensory stimuli controlled by deep cortical interneurons. Nature 457, 1137-1141. doi: 10.1038/nature07663

Nevian, T., and Sakmann, B. (2006). Spine Ca2+ signaling in spiketiming-dependent plasticity. J. Neurosci. 26, 11001-11013. doi: 10.1523/JNEUROSCI.1749-06.2006

Nissen, W., Szabo, A., Somogyi, J., Somogyi, P., and Lamsa, K. P. (2010). Cell type-specific long-term plasticity at glutamatergic synapses onto hippocampal interneurons expressing either parvalbumin or CB1 cannabinoid receptor. J. Neurosci. 30, 1337-1347. doi: 10.1523/JNEUROSCI. 3481-09.2010

Oswald, A. M., and Reyes, A. D. (2008). Maturation of intrinsic and synaptic properties of layer $2 / 3$ pyramidal neurons in mouse auditory cortex. J. Neurophysiol. 99, 2998-3008. doi: 10.1152/jn.01160.2007

Paoletti, P., Bellone, C., and Zhou, Q. (2013). NMDA receptor subunit diversity: impact on receptor properties, synaptic plasticity and disease. Nat. Rev. Neurosci. 14, 383-400. doi: 10.1038/nrn3504

Patel, A. B., Hays, S. A., Bureau, I., Huber, K. M., and Gibson, J. R. (2013). A target cell-specific role for presynaptic Fmrl in regulating glutamate release onto neocortical fast-spiking inhibitory neurons. J. Neurosci. 33, 2593-2604. doi: 10.1523/JNEUROSCI.2447-12.2013

Pelkey, K. A., and McBain, C. J. (2007). Differential regulation at functionally divergent release sites along a common axon. Curr. Opin. Neurobiol. 17, 366-373. doi: 10.1016/j.conb.2007.04.008

Pfister, J. P., Dayan, P., and Lengyel, M. (2010). Synapses with short-term plasticity are optimal estimators of presynaptic membrane potentials. Nat. Neurosci. 13, 1271-1275. doi: 10.1038/nn.2640

Pi, H. J., Hangya, B., Kvitsiani, D., Sanders, J. I., Huang, Z. J., and Kepecs, A. (2013). Cortical interneurons that specialize in disinhibitory control. Nature doi: 10.1038/nature12676. [Epub ahead of print].

Pike, F. G., Meredith, R. M., Olding, A. W., and Paulsen, O. (1999). Rapid report: postsynaptic bursting is essential for 'Hebbian' induction of associative longterm potentiation at excitatory synapses in rat hippocampus. J. Physiol. 518( $\mathrm{Pt}$ 2), 571-576. doi: 10.1111/j.1469-7793.1999.0571p.x

Planert, H., Szydlowski, S. N., Hjorth, J. J., Grillner, S., and Silberberg, G. (2010). Dynamics of synaptic transmission between fast-spiking interneurons and striatal projection neurons of the direct and indirect pathways. J. Neurosci. 30, 3499-3507. doi: 10.1523/JNEUROSCI.5139-09.2010

Pouille, F., and Scanziani, M. (2004). Routing of spike series by dynamic circuits in the hippocampus. Nature 429, 717-723. doi: 10.1038/nature02615

Pouzat, C., and Hestrin, S. (1997). Developmental regulation of basket/stellate cell-> Purkinje cell synapses in the cerebellum. J. Neurosci. 17, 9104-9112.

Regalado, M. P., Terry-Lorenzo, R. T., Waites, C. L., Garner, C. C., and Malenka, R. C. (2006). Transsynaptic signaling by postsynaptic synapse-associated protein 97. J. Neurosci. 26, 2343-2357. doi: 10.1523/JNEUROSCI.5247-05.2006

Regehr, W. G., Carey, M. R., and Best, A. R. (2009). Activity-dependent regulation of synapses by retrograde messengers. Neuron 63, 154-170. doi: 10.1016/j.neuron.2009.06.021

Reyes, A., Lujan, R., Rozov, A., Burnashev, N., Somogyi, P., and Sakmann, B. (1998). Target-cell-specific facilitation and depression in neocortical circuits. Nat. Neurosci. 1, 279-285. doi: 10.1038/1092

Reyes, A., and Sakmann, B. (1999). Developmental switch in the short-term modification of unitary EPSPs evoked in layer $2 / 3$ and layer 5 pyramidal neurons of rat neocortex. J. Neurosci. 19, 3827-3835.

Rossi, B., Maton, G., and Collin, T. (2008). Calcium-permeable presynaptic AMPA receptors in cerebellar molecular layer interneurones. J. Physiol. 586, 5129-5145. doi: 10.1113/jphysiol.2008.159921

Rossi, B., Ogden, D., Llano, I., Tan, Y. P., Marty, A., and Collin, T. (2012). Current and calcium responses to local activation of axonal NMDA receptors in developing cerebellar molecular layer interneurons. PLOS ONE 7:e39983. doi: 10.1371/journal.pone.0039983
Rozov, A., and Burnashev, N. (1999). Polyamine-dependent facilitation of postsynaptic AMPA receptors counteracts paired-pulse depression. Nature 401, 594-598. doi: 10.1038/44151

Rozov, A., Burnashev, N., Sakmann, B., and Neher, E. (2001). Transmitter release modulation by intracellular $\mathrm{Ca} 2+$ buffers in facilitating and depressing nerve terminals of pyramidal cells in layer $2 / 3$ of the rat neocortex indicates a target cell-specific difference in presynaptic calcium dynamics. J. Physiol. 531, 807-826. doi: 10.1111/j.1469-7793.2001.0807h.x

Ruiz, A. J., and Kullmann, D. M. (2012). Ionotropic receptors at hippocampal mossy fibers: roles in axonal excitability, synaptic transmission, and plasticity. Front. Neural Circuits 6:112. doi: 10.3389/fncir.2012.00112

Sala, C., Piech, V., Wilson, N. R., Passafaro, M., Liu, G., and Sheng, M. (2001). Regulation of dendritic spine morphology and synaptic function by Shank and Homer. Neuron 31, 115-130. doi: 10.1016/S0896-6273(01) 00339-7

Salin, P. A., Scanziani, M., Malenka, R. C., and Nicoll, R. A. (1996). Distinct shortterm plasticity at two excitatory synapses in the hippocampus. Proc. Natl. Acad. Sci. U.S.A. 93, 13304-13309. doi: 10.1073/pnas.93.23.13304

Sara, Y., Biederer, T., Atasoy, D., Chubykin, A., Mozhayeva, M. G., Sudhof, T. C., et al. (2005). Selective capability of SynCAM and neuroligin for functional synapse assembly. J. Neurosci. 25, 260-270. doi: 10.1523/JNEUROSCI.316504.2005

Saviane, C., and Silver, R. A. (2006). Fast vesicle reloading and a large pool sustain high bandwidth transmission at a central synapse. Nature 439, 983-987. doi: 10.1038 /nature04509

Scanziani, M., Gahwiler, B. H., and Charpak, S. (1998). Target cell-specific modulation of transmitter release at terminals from a single axon. Proc. Natl. Acad. Sci. U.S.A. 95, 12004-12009. doi: 10.1073/pnas.95.20.12004

Scott, R., Lalic, T., Kullmann, D. M., Capogna, M., and Rusakov, D. A. (2008). Target-cell specificity of kainate autoreceptor and $\mathrm{Ca} 2+$-store-dependent short-term plasticity at hippocampal mossy fiber synapses. J. Neurosci. 28, 13139-13149. doi: 10.1523/JNEUROSCI.2932-08.2008

Shigemoto, R., Kulik, A., Roberts, J. D., Ohishi, H., Nusser, Z., Kaneko, T., et al. (1996). Target-cell-specific concentration of a metabotropic glutamate receptor in the presynaptic active zone. Nature 381, 523-525. doi: 10.1038/ $381523 \mathrm{a} 0$

Silberberg, G., and Markram, H. (2007). Disynaptic inhibition between neocortical pyramidal cells mediated by Martinotti cells. Neuron 53, 735-746. doi: 10.1016/j.neuron.2007.02.012

Silberberg, G., Wu, C., and Markram, H. (2004). Synaptic dynamics control the timing of neuronal excitation in the activated neocortical microcircuit. J. Physiol. 556, 19-27. doi: 10.1113/jphysiol.2004.060962

Sjöström, P. J., and Häusser, M. (2006). A cooperative switch determines the sign of synaptic plasticity in distal dendrites of neocortical pyramidal neurons. Neuron 51, 227-238. doi: 10.1016/j.neuron.2006.06.017

Sjöström, P. J., Rancz, E. A., Roth, A., and Häusser, M. (2008). Dendritic Excitability and Synaptic Plasticity. Physiol. Rev. 88, 769-840. doi: 10.1152/physrev.00016.2007

Sjöström, P. J., Turrigiano, G. G., and Nelson, S. B. (2003). Neocortical LTD via coincident activation of presynaptic NMDA and cannabinoid receptors. Neuron 39, 641-654. doi: 10.1016/S0896-6273(03)00476-8

Sjöström, P. J., Turrigiano, G. G., and Nelson, S. B. (2007). Multiple forms of longterm plasticity at unitary neocortical layer 5 synapses. Neuropharmacology 52, 176-184. doi: 10.1016/j.neuropharm.2006.07.021

Stan, A., Pielarski, K. N., Brigadski, T., Wittenmayer, N., Fedorchenko, O., Gohla, A., et al. (2010). Essential cooperation of N-cadherin and neuroligin-1 in the transsynaptic control of vesicle accumulation. Proc. Natl. Acad. Sci. U.S.A. 107, 11116-11121. doi: 10.1073/pnas.0914233107

Sun, H. Y., and Dobrunz, L. E. (2006). Presynaptic kainate receptor activation is a novel mechanism for target cell-specific short-term facilitation at Schaffer collateral synapses. J. Neurosci. 26, 10796-10807. doi: 10.1523/JNEUROSCI.274606.2006

Sun, H. Y., Lyons, S. A., and Dobrunz, L. E. (2005). Mechanisms of target-cell specific short-term plasticity at Schaffer collateral synapses onto interneurones versus pyramidal cells in juvenile rats. J. Physiol. 568, 815-840. doi: 10.1113/jphysiol.2005.093948

Sussillo, D., Toyoizumi, T., and Maass, W. (2007). Self-tuning of neural circuits through short-term synaptic plasticity. J Neurophysiol 97, 4079-4095. doi: 10.1152/jn.01357.2006 
Sylwestrak, E. L., and Ghosh, A. (2012). Elfn1 regulates target-specific release probability at CA1-interneuron synapses. Science 338, 536-540. doi: 10.1126/science. 1222482

Takeichi, M. (2007). The cadherin superfamily in neuronal connections and interactions. Nat. Rev. Neurosci. 8, 11-20. doi: 10.1038/nrn2043

Takeichi, M., and Abe, K. (2005). Synaptic contact dynamics controlled by cadherin and catenins. Trends Cell Biol. 15, 216-221. doi: 10.1016/j.tcb.2005.02.002

Takesian, A. E., Kotak, V. C., and Sanes, D. H. (2010). Presynaptic GABA(B) receptors regulate experience-dependent development of inhibitory short-term plasticity. J. Neurosci. 30, 2716-2727. doi: 10.1523/JNEUROSCI.3903-09.2010

Takesian, A. E., Kotak, V. C., Sharma, N., and Sanes, D. H. (2013). Hearing loss differentially affects thalamic drive to two cortical interneuron subtypes. J. Neurophysiol. 110, 999-1008. doi: 10.1152/jn.00182.2013

Tang, A. H., Chai, Z., and Wang, S. Q. (2007). Dark rearing alters the shortterm synaptic plasticity in visual cortex. Neurosci. Lett. 422, 49-53. doi: 10.1016/j.neulet.2007.05.053

Thomson, A. M. (1997). Activity-dependent properties of synaptic transmission at two classes of connections made by rat neocortical pyramidal axons in vitro. J. Physiol. 502(Pt 1), 131-147. doi: 10.1111/j.1469-7793.1997.131bl.x

Thomson, A. M. (2003). Presynaptic frequency- and pattern-dependent filtering. J. Comput. Neurosci. 15, 159-202. doi: 10.1023/A:1025812808362

Thomson, A. M., Deuchars, J., and West, D. C. (1996). Neocortical local synaptic circuitry revealed with dual intracellular recordings and biocytin-filling. J. Physiol. Paris 90, 211-215. doi: 10.1016/S0928-4257(97)81425-8

Toth, K., and McBain, C. J. (2000). Target-specific expression of pre- and postsynaptic mechanisms. J. Physiol. 525(Pt 1), 41-51. doi: 10.1111/j.14697793.2000.00041.x

Toth, K., Suares, G., Lawrence, J. J., Philips-Tansey, E., and McBain, C. J. (2000). Differential mechanisms of transmission at three types of mossy fiber synapse. J. Neurosci. 20, 8279-8289.

Tsodyks, M., Pawelzik, K., and Markram, H. (1998). Neural networks with dynamic synapses. Neural Comput. 10, 821-835. doi: 10.1162/089976698300017502

Tsodyks, M., Uziel, A., and Markram, H. (2000). Synchrony generation in recurrent networks with frequency-dependent synapses. J. Neurosci. 20, RC50.

Tsodyks, M. V., and Markram, H. (1997). The neural code between neocortical pyramidal neurons depends on neurotransmitter release probability. Proc. Natl. Acad. Sci. U.S.A. 94, 719-723. doi: 10.1073/pnas.94.2.719

Varela, J. A., Sen, K., Gibson, J., Fost, J., Abbott, L. F., and Nelson, S. B. (1997). A quantitative description of short-term plasticity at excitatory synapses in layer 2/3 of rat primary visual cortex. J. Neurosci. 17, 7926-7940.

Varela, J. A., Song, S., Turrigiano, G. G., and Nelson, S. B. (1999). Differential depression at excitatory and inhibitory synapses in visual cortex. J. Neurosci. 19, 4293-4304.

Varoqueaux, F., Aramuni, G., Rawson, R. L., Mohrmann, R., Missler, M., Gottmann, K., et al. (2006). Neuroligins determine synapse maturation and function. Neuron 51, 741-754. doi: 10.1016/j.neuron.2006.09.003

Vitureira, N., Letellier, M., White, I. J., and Goda, Y. (2012). Differential control of presynaptic efficacy by postsynaptic N-cadherin and beta-catenin. Nat. Neurosci. 15, 81-89. doi: 10.1038/nn.2995

Wang, L., Fontanini, A., and Maffei, A. (2012). Experience-dependent switch in sign and mechanisms for plasticity in layer 4 of primary visual cortex. J. Neurosci. 32, 10562-10573. doi: 10.1523/JNEUROSCI.0622-12.2012
Wang, Y., Markram, H., Goodman, P. H., Berger, T. K., Ma, J., and Goldman-Rakic, P. S. (2006). Heterogeneity in the pyramidal network of the medial prefrontal cortex. Nat. Neurosci. 9, 534-542. doi: 10.1038/nn1670

Wasling, P., Hanse, E., and Gustafsson, B. (2004). Developmental changes in release properties of the CA3-CA1 glutamate synapse in rat hippocampus. J. Neurophysiol. 92, 2714-2724. doi: 10.1152/jn.00464.2004

Williams, S. R., and Stuart, G. J. (2002). Dependence of EPSP efficacy on synapse location in neocortical pyramidal neurons. Science 295, 1907-1910. doi: 10.1126/science. 1067903

Wilson, N. R., Runyan, C. A., Wang, F. L., and Sur, M. (2012). Division and subtraction by distinct cortical inhibitory networks in vivo. Nature 488, 343-348. doi: 10.1038/nature11347

Wittenmayer, N., Korber, C., Liu, H., Kremer, T., Varoqueaux, F., Chapman, E. R., et al. (2009). Postsynaptic Neuroligin1 regulates presynaptic maturation. Proc. Natl. Acad. Sci. U.S.A. 106, 13564-13569. doi: 10.1073/pnas.0905819106

Yanagisawa, T., Tsumoto, T., and Kimura, F. (2004). Transiently higher release probability during critical period at thalamocortical synapses in the mouse barrel cortex: relevance to differential short-term plasticity of AMPA and NMDA EPSCs and possible involvement of silent synapses. Eur. J. Neurosci. 20, 3006-3018. doi: 10.1111/j.1460-9568.2004.03756.x

Zhang, W., and Linden, D. J. (2006). Long-term depression at the mossy fiber-deep cerebellar nucleus synapse. J. Neurosci. 26, 6935-6944. doi: 10.1523/JNEUROSCI.0784-06.2006

Zhang, Z. W. (2004). Maturation of layer V pyramidal neurons in the rat prefrontal cortex: intrinsic properties and synaptic function. J. Neurophysiol. 91, 1171-1182. doi: 10.1152/jn.00855.2003

Zhou, N., Rungta, R. L., Malik, A., Han, H., Wu, D. C., and Macvicar, B. A. (2013). Regenerative glutamate release by presynaptic NMDA receptors contributes to spreading depression. J. Cereb. Blood Flow Metab. 33, 1582-1594. doi: $10.1038 /$ jcbfm.2013.113

Zucker, R. S., and Regehr, W. G. (2002). Short-term synaptic plasticity. Annu. Rev. Physiol. 64, 355-405. doi: 10.1146/annurev.physiol.64.092501.114547

Conflict of Interest Statement: The authors declare that the research was conducted in the absence of any commercial or financial relationships that could be construed as a potential conflict of interest.

Received: 30 July 2013; accepted: 07 November 2013; published online: 06 December 2013.

Citation: Blackman AV, Abrahamsson T, Costa RP, Lalanne T and Sjöström PJ (2013) Target-cell-specific short-term plasticity in local circuits. Front. Synaptic Neurosci. 5:11. doi: 10.3389/fnsyn.2013.00011

This article was submitted to the journal Frontiers in Synaptic Neuroscience.

Copyright (C) 2013 Blackman, Abrahamsson, Costa, Lalanne and Sjöström. This is an open-access article distributed under the terms of the Creative Commons Attribution License (CC BY). The use, distribution or reproduction in other forums is permitted, provided the original author(s) or licensor are credited and that the original publication in this journal is cited, in accordance with accepted academic practice. No use, distribution or reproduction is permitted which does not comply with these terms. 